\title{
Plasma polymerized bioceramics for drug delivery: Do surface changes alter biological behaviour?
}

\author{
Kanupriya Khurana ${ }^{\mathrm{a}, \mathrm{b}, \mathrm{c}}$, Frank Müller ${ }^{\mathrm{d}}$, Karin Jacobs ${ }^{\mathrm{d}}$, Thomas Faidt ${ }^{\mathrm{d}}$, Jens-Uwe Neurohr ${ }^{\mathrm{d}}$, Samuel \\ Grandthyll $^{\mathrm{d}}$, Frank Mücklich ${ }^{\mathrm{c}}$, Cristina Canal ${ }^{\mathrm{a}, \mathrm{b}^{*}}$, Maria Pau Ginebra ${ }^{\mathrm{a}, \mathrm{b}, \mathrm{e}}$ \\ ${ }^{a}$ Biomaterials, Biomechanics and Tissue Engineering Group, Dpt. Materials Science and Metallurgy, \\ Universitat Politècnica de Catalunya (UPC), Av. Eduard Maristany 10-14, 08019 Barcelona, Spain. \\ ${ }^{b}$ Research centre in Multiscale Science and Engineering, UPC, Barcelona, Spain \\ ${ }^{c}$ Chair of Functional Materials, Department of Material Science and Engineering, Saarland University, \\ Germany. \\ ${ }^{d}$ Department of Physics, Saarland University, Germany \\ ${ }^{e}$ Institute of Bioengineering of Catalonia (IBEC), Baldiri i Reixach 10-12, 08028 Barcelona, Spain.
}

\begin{abstract}
One of the treatments for recurrent or complicated osteomyelitis is by local antibiotherapy mediated by suitable bone grafts. $\beta$-Tricalcium Phosphate $(\beta-\mathrm{TCP})$ bioceramic is a resorbable bone graft. Its microporosity allows for incorporation of drugs, but a too fast release is often obtained. Complex strategies have been explored to obtain controlled drug release. In this work, plasma polymerization of a biocompatible polymer was investigated on $\beta$-TCP. Polyethyleneglycol (PEG)-like polymer coatings of different thickness were deposited on microporous $\beta$-TCP loaded with antibiotics. A highly hydrophobic surface was obtained despite the hydrophilicity of the PEG-like layer produced, which was associated to the roughness of the $\beta$-TCP substrate. The bioceramics nevertheless retained their suitable biological behavior with regard to human osteoblast cells. The microbiological activity of the antibiotics was preserved, and the coatings reduced the total amount of drug released as a function of the increasing plasma treatment time.
\end{abstract}

Keywords: Plasma polymerization, $\beta$-Tricalcium Phosphate, PEG-like polymer, antibiotics, drug release, biocompatibility.

\section{Introduction}

Osteomyelitis is a bone infection. It can spring from different causes: i) from spreading of bacteria originating from an infection elsewhere in the body, ii) through an open wound over a bone or iii) after the exposure of bone to bacteria during a surgery or an injection around a bone. The most usual treatments involve administration of antibiotics, but sometimes surgery may be necessary, and whenever bone is damaged it requires removal and replacement with a bone graft [1] Systemic antibiotic regimes are used for four to eight weeks depending on the pathogenic bacteria and the response of the patient. But with long delays in

\footnotetext{
*Corresponding author.

Email addresses: cristina.canaleupc.edu (Cristina Canal)
} 
diagnosis or treatment, significant bone damage; or if the initial treatment is not effective, patients are more prone to reoccurrence and the condition can become chronic and difficult to eradicate $[2,3]$.

The delivery and maintenance of therapeutic levels of antibiotic at the site of infection can be achieved by using implants or carriers that release antibiotics locally; these have significantly improved the treatment of osteomyelitis [4]. Many local antibiotic releasing systems have been developed in recent years, and several are available for clinical use, such as polymethylmethacrylate (PMMA) beads, collagen, apatite-wollastonite glass ceramic blocks, hydroxyapatite blocks, polylactide/polyglycolide implants, and polylactate polymers [3, 5-7]. Among these PMMA rosary beads impregnated with gentamicin have been often employed in the clinics, but they have several disadvantages, especially the need to remove the foreign material surgically under general anaesthesia [5, 6, 8-10].

An ideal local carrier should be biocompatible and biodegradable, and in applications requiring bone substitution, it should be resorbable and able to promote bone formation. Many calcium phosphates ( $\mathrm{CaPs}$ ) have been widely employed as bone grafts and many of them are in the market. Among them, $\beta$-tricalcium phosphate $(\beta-\mathrm{TCP})$ is an interesting bioceramic obtained at high temperatures with higher solubility than i.e. hydroxyapatite and that has been widely employed in reconstructive surgery [11] due to its resorbability and ability to promote new bone formation [12-14].

$\beta$-TCP has been evaluated as drug delivery system of different drugs. For example, in the release of gentamicin fast release was obtained in the first day and different strategies, more or less complex were evaluated to control this release [15]. Different works have relied in producing composite materials from $\beta$-TCP or other CaPs and biocompatible polymers (such as chitosan, gelatin, etc.) $[16,17]$; to improve different features of the material, among which to modulate drug release from the matrices. However, this approach usually involves complex processing stages. Plasma polymerization is a versatile technique for the deposition of films with functional properties suitable for a wide range of applications [18, 19]. Although plasma polymerization is a well-studied field, its application to bioceramics is rather recent. In a recent work, we proposed plasma polymerization of a hydrophilic polyethyleneglycol (PEG)-like layer as a dry method allowing to coat $\beta$-TCP [20]. In that work, the coating produced allowed to successfully modify drug release kinetics, avoiding burst release, and slowing down the initial rate of release. However, the coatings produced by plasma polymerization led to very hydrophobic surfaces. This change in wettability could have a critical impact on the biological behaviour of these bioceramics.

Herein, we aim at investigating in-depth the origins of this unexpected hydrophobicity, with a particular focus on its effects on biological behaviour. Therein, $\beta$-TCP has been subjected to plasma polymerization to obtain PEG-like coatings, by using single and multi- step coatings, and the modified surfaces have been characterized. To ascertain the barrier effect of the coatings developed, the release of two different antibiotics (gentamicin and ampicillin) has been evaluated from these bioceramics, and their microbiological behaviour has been studied after the plasma polymerization process undergone by the samples.

February 16, 2018 


\section{Material and methods}

\subsection{Materials}

Calcium hydrogen phosphate $\left(\mathrm{CaHPO}_{4}\right.$, Sigma-Aldrich C7263) and calcium carbonate $\left(\mathrm{CaCO}_{3}\right.$, Sigma-Aldrich $\left.\mathrm{C} 4830\right)$ were used as raw materials for the synthesis of $\beta$-tricalcium phosphate $\left(\beta-\mathrm{Ca}_{3}\left(\mathrm{PO}_{4}\right)_{2}, \beta\right.$-TCP). Sodium phosphate dibasic $\left(\mathrm{Na}_{2} \mathrm{HPO}_{4}\right.$, Sigma-Aldrich) was used in solution as accelerant in the synthesis of calcium deficient hydroxyapatite (CDHA) used as a precursor of $\beta$-TCP. Ampicillin sodium salt $(371.39 \mathrm{~g} / \mathrm{mol} ; 50 \mathrm{mg} / \mathrm{ml}$ in water), and gentamicin sulphate $(477.6 \mathrm{~g} / \mathrm{mol}, 50 \mathrm{mg} / \mathrm{ml}$ in water $)$ provided by Sigma- Aldrich were selected as antibiotics for loading $\beta$-TCP ceramics (supplementary material Figure S1). Diethylene glycol dimethyl ether (Diglyme, anhydrous, 99.5\%, Sigma Aldrich) $\left(\mathrm{CH}_{3} \mathrm{OCH}_{2} \mathrm{CH}_{2}\right)_{2} \mathrm{O}$ was used as precursor for plasma polymerization. Phosphate buffer saline (PBS), pH 7.4, was prepared from PBS Tablets (Gibco, LifetechnologiesTM, UK) and Milli$\mathrm{Q}^{\mathbb{R}}$ deionized water. Agar bacteriological (Scharlau S.A., Spain) and Brain Heart Infusion Broth (BHI Broth) (Scharlau S.A., 02-599, Spain) were used to prepare the bacteriological culture media of Staphylococcus aureus (S. aureus), (Culture Collection University of Göteborg (CCUG 15915), Sweden).

\section{2. $\beta$-TCP Synthesis}

Microporous $\beta$-TCP discs were obtained by thermal treatment of calcium deficient hydroxyapatite (CDHA), which was in turn obtained through the setting reaction of an $\alpha-$ TCP calcium phosphate cement. $\alpha$-TCP was obtained by solid state reaction of a 1:2 molar mixture of calcium hydrogen phosphate and calcium carbonate at $1400^{\circ} \mathrm{C}$. A cement was produced by blending $\alpha$-TCP with a solution of sodium phosphate dibasic at $2.5 \%$ $(w: w)$ at liquid to powder ratio of 0.65 . The mixture was put in a disc-shaped mould and allowed to set immersed in water for 7 days to obtain CDHA, as described in [21]. The former discs were sintered at $1100{ }^{\circ} \mathrm{C}$ to obtain microporous $\beta$-TCP discs of $2 \mathrm{~mm}$ thickness $12 \mathrm{~mm} \varnothing$. This allowed obtaining a 100\% $\beta$-TCP material, according to XRD (not shown).

\subsection{Plasma Polymerization}

Plasma polymerization of $\beta$-TCP discs was performed using low-pressure radio-frequency plasma (13.56 MHz) (Standard Femto Plasma System, Diener, Germany) with a cylindrical glass chamber. Diglyme was used as source of ethylene oxide monomers to obtain a PEGlike coating on $\beta$-TCP [22]. Unloaded or antibiotic-loaded $\beta$-TCP discs were placed in the centre of the reactor. To enhance the polymerization process a short surface activation step with $\mathrm{O}_{2}(5.0 \mathrm{sccm}, 0.40 \mathrm{mbar}, 150 \mathrm{~W})$ was performed for $60 \mathrm{~s}$. The subsequent polymerization process consists in introducing Diglyme in the plasma reactor by bubbling a carrier gas (Ar) through the liquid monomer. The polymerization treatment performed in continuous mode $(15 \mathrm{sccm}, 1.70 \mathrm{mbar}, 150 \mathrm{~W})$ for $10 \mathrm{~min}$ is labelled as plasma polymerization (PP10). Repetition of the polymerization cycle in the same conditions described, without removing the samples from the reactor was designed for $20 \mathrm{~min}, 30 \mathrm{~min}$ or $40 \mathrm{~min}$ polymerizations were performed on each side of the $\beta$-TCP materials, and the corresponding samples were referenced as PP20, PP30 and PP40 respectively (Figure 1). 


\subsection{Surface Topography}

Topography of untreated and plasma polymerized $\beta$-TCP discs were studied by Scanning Electron Microscopy using a Zeiss Neon 40 cross-beam workstation with Gemini SEM column for sample observation. Samples were carbon-coated before SEM observation. Observations were carried out at $5.0 \mathrm{kV}$ working voltage. Coupled-Energy-Dispersive X-ray spectroscopy (EDX) equipment (INCAPentaFETx3 detector, $30 \mathrm{~mm}^{2}$, ATW2 window) was also used for in situ elemental analysis of the surface of a cross-section of plasma-polymerized $\beta$-TCP to determine the depth of the effects of plasma treatment on the surface of the bioceramic materials.

\subsection{Wetting Properties}

Determination of the wettability of the $\beta$-TCP surfaces, to compare the untreated with the PEG-coated ceramics by plasma polymerization was done by static and dynamic contact angle measurements. A Contact Angle System OCA15 (Dataphysics, Germany) was used with the SCA20 Software (Dataphysics, Germany) to analyse the images acquired with a CCD. In static, $10 \mu \mathrm{L}$ water droplet were deposited on the $\beta$-TCP surface and in dynamic, volume changes continuously. Measurements were carried out on the plasma-polymerized side of the samples. In this study, a minimum of 5 replicates of each kind of treatment were carried out.

Dynamic contact angles were calculated as follows: Advancing contact angles were measured by increasing the volume of the water drop, until the contact angle remained constant. Receding contact angles were measured by decreasing the volume of the drop until the con- tact angle value remained constant and the solid/liquid interface started to decrease. Values reported result from the average of at least 6 replicates measured in independent samples.

The contact angle hysteresis was calculated as the difference between dynamic advancing and receding contact angles, according to equation 1.

$$
\Delta \theta=\theta_{a d v}-\theta_{\text {rec }}
$$

\subsection{Chemical Characterization}

To determine the chemical composition of the surface of bare and treated $\beta$-TCP samples and assess the influence of plasma polymerization, X-ray photoelectron spectroscopy (XPS) experiments were performed with a ESCALab MKII spectrometer by Vacuum Generators using non-monochromatic Al-Ka radiation (photon energy $1486.6 \mathrm{eV}$ ) in normal emission mode (i.e. photoelectrons were detected along the surface normal of the samples). Survey spectra were recorded at reduced energy resolution at pass energy of $50 \mathrm{eV}$, while the detail spectra of $\mathrm{C}_{1 s}, \mathrm{Ca}_{2 \mathrm{p}}, \mathrm{Ca}_{2 \mathrm{~s}}, \mathrm{P}_{2 \mathrm{p}}, \mathrm{P}_{2 s}$ and $\mathrm{O}_{1 s}$ were recorded at pass energy of $10 \mathrm{eV}$. For estimating the distribution of elements in terms of at $-\%$ the intensity of the photoemission peaks (as obtained after Shirley-type background correction) were weighted with the photoemission cross sections. The relative error associated to the XPS measurements is about $5 \%$.

Fourier Transform Infrared Spectra were recorded using a FTIR Nicolet 6700 in the transmittance mode, (128 scans and resolution 1 with data spacing $\left.0.482 \mathrm{~cm}^{-1}\right)$. Si wafer were used as the substrate instead of $\beta$-TCP disc for the FTIR measurement. 


\subsection{Ampicillin and Gentamicin Loading of $\beta-T C P$}

Loading of ampicillin and gentamicin was done prior to plasma polymerization; by soaking the $\beta$-TCP discs in $1.0 \mathrm{~mL}$ of $4.0 \%$ aqueous drug solution at 100 r.p.m. and $24-27$ ${ }^{\circ} \mathrm{C}$ during $30 \mathrm{~min}$, by complete immersion of the sample. Samples were dried at $37{ }^{\circ} \mathrm{C}$ for 24 $\mathrm{h}$ prior to release studies.

\subsection{Drug Release Experiments}

Ampicillin and gentamicin release experiments were performed using untreated and plasma-polymerized $\beta$-TCP discs previously loaded with the $4.0 \%$ solution of drugs respectively. Details of the amount of drug loaded in each kind of samples devoted to drug release are provided in supplementary material (Table S1). The assay included samples loaded with drug (D) (ampicillin (AMP) or gentamicin (GENTA): UT-D; PP10-D, PP20-D, PP30-D and PP40-D) and untreated samples. For the drug release study, an USP equipment (TDT08L Dissolution Tester (USP), Pharma Alliance Group, U.S.A.) with 8 thermo- jacketed opaque cells of $300 \mathrm{~mL}$ was used, each one filled with $150 \mathrm{~mL}$ of PBS at $\mathrm{pH} 7.4$ as receptor media. Temperature and rotation were maintained constant at $37{ }^{\circ} \mathrm{C}$ and 100 r.p.m. respectively. $1 \mathrm{~mL}$ samples were withdrawn from the receptor liquid media for release concentration analysis from the untreated and plasma-polymerized $\beta$-TCP discs. After each sample withdrawn, the same volume of PBS was added to the receptor media. Release experiments were performed with four replicates of each plasma polymerization condition.

For the quantification of the ampicillin release, an UV-visible-NIR spectrophotometer UV-3600 Shimadzu was used at $\lambda=204 \mathrm{~nm}$, corresponding to the wavelength of maximum absorbance of ampicillin in PBS solution. The concentration of ampicillin was below $10 \%$ saturation concentration (SINK conditions) in the receptor solution during the experiment. Stability of ampicillin after plasma polymerization on the ampicillin-loaded $\beta$-TCP was also checked by UV- spectroscopy after release of ampicillin in PBS through comparison of the general spectra. The amount of gentamicin released was obtained by measuring the release media collected at each time point by High Performance Liquid Chromatography (HPLC) in a Shimadzu HPLC system. Mobile phase consisted of methanol-water-ammonium acetate buffer $(0.02 \mathrm{M}$, adjusted with concentrate ammonia to $\mathrm{pH}=9): 35: 60: 5(\mathrm{v} / \mathrm{v} / \mathrm{v})$, at a flow rate of $0.3 \mathrm{ml} / \mathrm{min}$ was passed through a C8 column (Shim-pack, Shimadzu). An injection volume of $20 \mu \mathrm{l}$ of the release sample was measured by photodiode array (PDA) at $\lambda_{\max }=238 \mathrm{~nm}$ corresponding to the wavelength of maximum absorbance of gentamicin in PBS solution. Stability of gentamicin after plasma polymerization on the gentamicin-loaded $\beta$-TCP was also checked by HPLC after release of gentamicin in PBS through comparison of the control spectra.

The kinetic models used were Zero order equation $\left(\mathrm{Q}_{t}=\mathrm{Q}_{0}-\mathrm{K}_{0} \mathrm{t}\right)$ and Kopcha kinetics $\left(\mathrm{Q}_{t}=\mathrm{A}_{\mathrm{t}_{1 / 2}}+\mathrm{B}_{\mathrm{t}}\right)\left[\mathrm{Q}_{0}\right.$ is the initial amount of drug in the solution $\mathrm{Q}_{0}=0, \mathrm{~K}_{0}$ is the zero order release constant and $\mathrm{Q}_{t}$ is the amount of drug released at time $\mathrm{t}, \mathrm{A}=$ diffusional constant and $\mathrm{B}=$ erosion constant].

\subsection{Antibacterial Assay}

The antibacterial activity of the ampicillin and gentamicin loaded plasma polymerized $\beta$ TCP discs were tested in suspension against Staphylococcus aureus ( $S$. aureus) in BHI Broth at $[\mathrm{BHI}]=37.0 \mathrm{~g} . \mathrm{L}^{-1}$. After incubation for $24 \mathrm{~h}$ at $37^{\circ} \mathrm{C}, 1 \mathrm{~mL}$ of the inoculate media was put in each well of a 48 -well Falcon ${ }^{\mathrm{TM}}$ culture well-plates, previously prepared by connecting 
two adjacent wells. The optical density of bacterial suspension was adjusted to $0.2 \pm 0.01$ at $600 \mathrm{~nm}$, giving approximately 1 x 108 colony-forming units $(\mathrm{CFU}) / \mathrm{ml}$. The assay was conducted with samples loaded with drug (D) (ampicillin (AMP) or gentamicin (GENTA): UT-D; PP10-D, PP20-D, PP30-D and PP40-D) and samples without antibiotics that were treated as controls (untreated $\beta$-TCP: UT, untreated $\beta$-TCP with 40 min polymerization: PP40 Samples) apart from controls of $S$. aureus Ctrl+ (with bacteria) and Ctrl- (bacteria growth medium without bacteria). Later, samples were placed in one of the connected wells, while the second was employed to measure absorbance and monitoring the growth of S. aureus by means of a Synergy HTX Multimode Reader (BioTek Instruments, Inc.). The antibacterial growth kinetics was monitored for $48 \mathrm{~h}$ at $\lambda=600 \mathrm{~nm}$ absorbance [23]. Measurements were recorded using Gen. 5 software (BioTek Instruments, Inc.) and results are presented in growth curve with standard deviation.

\subsection{Cell Biocompatibility}

The effect of the plasma coating on $\beta$-TCP discs on the interaction with osteoblastic cells was evaluated using a human osteosarcoma cell line (SaOS-2, ATCC, USA), with three replicates for each condition. The coated or uncoated $\beta$-TCP discs were sterilized by UV treatment for 15 min and placed in 24-well tissue polystyrene (TCPS) plates. SaOS-2 cells (80,000 cells/well) were seeded on the surface of the discs in McCoy's cell culture medium (Invitrogen, Carlsbad, CA, USA) and incubated at $37{ }^{\circ} \mathrm{C}$ for a week. Cell culture media was replaced at every 24 h. At 6 h, 24 h, 3 days and 7 days' time point, cells were lysed with 300 $\mu \mathrm{L}$ of M-PER ${ }^{\circledR}$ (Mammalian Protein Extraction Reagent, Thermo Scientific, Waltham, MA, USA). The cell number was evaluated using the Cytotoxicity Detection Kit LDH (Roche Applied Science, Penzberg, Germany), according to the manufacturer's instructions. The LDH activity was measured spectrophotometrically at $492 \mathrm{~nm}$ with PowerWave HT microplate reader (Bio-Tek Instruments, Inc.) 24. The results were expressed as a relative fold change compared to the cell number obtained on TCPS at $6 \mathrm{~h}$ (SaOS-2 cells). The cell viability was calculated following equation 2 , where Abs is the measured absorbance for the samples (Abs sample) and the positive $\left(\mathrm{Abs}_{C_{+}}\right)$and negative control $\left(\mathrm{Abs}_{C^{-}}\right)$, all the results have been normalized with respect to surface area of TCPS.

$$
\text { Cell viability }=\text { Abs sample }-\frac{A b s C-}{(A b s C+)-(A b s C-)}
$$

Eq. 2

Specimens were prepared for SEM observation by fixing the cells with $4 \%$ paraformaldehyde in PBS, and a sequence for dehydrating the cells was performed by immersing the samples in 50\%, 70\%, 90\%, 96\%, and 100\% (v/v) ethanol during $15 \mathrm{~min}$ each step. As the final step, samples were immersed in HDMS overnight and carbon coated.

\subsection{Statistical Analysis}

The data were analysed using Student's t-tests and one-way ANOVA Tables with Tukey's multiple comparison tests in order to evaluate statistically significant differences between sample groups. The differences were considered to be statistically significant when $\mathrm{p}<0.05$. All statistical analysis was performed with Minitab 16TM software (Minitab, Inc., State College, PA). 


\section{Results}

\subsection{Characterization of the plasma coatings on $\beta-T C P$}

Plasma polymer coatings were produced on $\beta$-TCP, based on the polymerization of Diglyme at low pressure. To assess the kind of polymer produced by the low temperature plasma process evaluated, FTIR was performed on a model Si flat surface (Figure 2). The hump observed at $3600 \mathrm{~cm}^{-1}$ can be attributed to adsorbed water, the other bands found were characteristic of polymers: Two weak bands at $2952 \mathrm{~cm}^{-1}$ and $2888 \mathrm{~cm}^{-1}$ which can be attributed to hydrocarbon stretching $\mathrm{v}(\mathrm{C}-\mathrm{H})$ in alkanes. A medium band at $1655 \mathrm{~cm}^{-1}$ and another at $1533 \mathrm{~cm}-1$ may correspond to $v(\mathrm{C}=\mathrm{O})$, and the shoulder at 1464 can probably be attributed to $v(\mathrm{C}-\mathrm{O})$. The intense bands at $1218 \mathrm{~cm}^{-1}$ and $1055 \mathrm{~cm}^{-1}$ can probably be assigned to $v$ as $(\mathrm{C}-\mathrm{O})$ and $v \mathrm{~s}(\mathrm{C}-\mathrm{O})$, respectively.

Uncoated $\beta$-TCP is a hydrophilic and porous material, and therefore it quickly absorbs water, not allowing contact angle measurement (Table 1). Furthermore, PEG being a hydrophilic polymer, its coatings should display contact angles below $90^{\circ}$, as recorded here for some selected plasma treatments on Silicon wafer employed as flat model surface (Figure 2). Surprisingly, this was not the case for the different plasma treatments evaluated on $\beta$ - TCP (Table 1) which displayed contact angle values above $120^{\circ}$, except for the PP10 sample that still absorbed water (although more slowly than the pristine material). It is remarkable that with PP20, PP30 or PP40 the droplet was strongly pinned to the surface, not rolling off even if the sample was held vertical (photographs in Figure 3).

Dynamic contact angles were also measured (Table 1), and allowed calculating hysteresis, which was high and similar in the three plasma coated samples.

The modification in surface chemistry indicated by contact angles was confirmed by XPS, by measuring the elemental composition of the untreated and plasma-polymerized $\beta$ - TCP (Table 2). The composition of untreated $\beta$-TCP copes very well with its theoretical concentration, with a $\mathrm{Ca} / \mathrm{P}$ ratio of 1.48 , and the presence of some $\mathrm{C}$ can be attributed to adsorbed ambient contamination or surface carbonates. The increase in $\mathrm{C} / \mathrm{O}$ ratio following all plasma polymerization treatments indicates the presence of a polymer. The fact that $\mathrm{Ca}$ or $\mathrm{P}$ was no longer detected pointed to a thickness of the polymer layer above $10 \mathrm{~nm}$ (i.e. the typical depth of detection of XPS). Figure 4 shows the $\mathrm{C}_{1 s}$ spectra of the PP40 PEG-like coatings, with three peaks. The two peaks at lower binding energies are the most prominent ones and correspond to carbon species with $\mathrm{C}-\mathrm{C}$ or $\mathrm{C}-\mathrm{H}$, and, $\mathrm{C}-\mathrm{O}$. The third peak at larger binding energy is mainly attributed to $\mathrm{C}=\mathrm{O}$. PP10, PP20 and PP30 showed very similar $\mathrm{C}_{1 s}$ spectra. Scanning electron micrographs (Figure 5, left) reflect the roughness and porosity of $\beta$ TCP. Moreover, following plasma polymerization SEM images clearly show that the coating itself is very thin, not masking any topographic features of $\beta$-TCP. At the same time, focused ion beam (FIB-SEM) transversal sections allowed visualizing (Figure 5, right) and measuring (Figure 6) the thickness of the coating as a function of the total treatment time of the plasma polymerization process.

Thickness ranged between $\sim 10 \mathrm{~nm}$ for PP10 to close to $\sim 38 \mathrm{~nm}$ for PP40, revealing increasing thickness with longer total plasma treatment times but not following a completely linear behaviour.

\subsection{Biological response}

February 16, 2018 
The changes in the wettability of the samples might affect the biological response of the material. Therefore, the cytocompatibility of the samples was evaluated through adhesion and proliferation assays (Figure 7). All PEG-like plasma-coated $\beta$-TCP samples displayed the same cell adhesion and proliferation than $\beta$-TCP for all conditions evaluated, with the sole exception of PP40, which showed slightly lower proliferation values at 1 and 7 days.

Scanning electron micrographs (Figure 8) show cells attached on the surface of $\beta$-TCP at different time points ( $6 \mathrm{~h} \& 3$ days). The morphology of the cells on all bioceramics showed extended cells, with visible fillopodia, disregard of the presence or absence of the coating.

\subsection{Drug Release}

Two different antibiotics were incorporated to the $\beta$-TCP ceramics prior to plasma coating: ampicillin (AMP) and gentamicin (GENTA). Their release kinetics was investigated following USP pharmacopoeia protocols for $24 \mathrm{~h}$ (Figure 9) and it can be observed that each drug follows a different release profile. On the one hand, ampicillin follows a burst release within the first $2 \mathrm{~h}$ in which most of the drug loaded is released (Figure 9). On the other hand, gentamicin follows a more progressive release during $24 \mathrm{~h}$ (Figure 9). Regarding the plasma coatings, it can be underlined that while for GENTA the total amount released decreases with the thicker plasma coating, the profile of release remains unaltered, for AMP slightly different profile is observed for the samples PP20-D, PP30-D and PP40-D, as shown in Figure 9.

The final release percentage of both drugs was close to $100 \%$ for the untreated $\beta$-TCP samples, while as plasma polymerization times were longer, the total release $\%$ progressively decreased by close to $20 \%$ (Table 3 ). The release kinetics was fitted to different models, being Kopcha's model the one showing best fitting. Fitting of the release data to Kopcha's model showed that the release kinetics are governed by diffusion phenomena, A/B being $>1$.

\subsection{Antibacterial properties}

The influence of plasma polymerization on the antibacterial activity of ampicillin and gentamicin was studied in a kinetic growth assay over $26 \mathrm{~h}$ (Figure 10). The growth activity of $S$. aureus was measured for plasma polymerized $\beta$-TCP with antibiotics (ampicillin; gentamicin): PP10-D, PP20-D, PP30-D, PP40-D and the bacterial growth in BHI medium was used as a control. It was observed that only the samples without antibiotic (bacterial suspension used as positive control, untreated $\beta$-TCP (UT) and $40 \mathrm{~min}$ plasma polymerized $\beta$-TCP (PP40) showed bacterial growth. On the contrary, samples loaded with antibiotics either untreated or coated with the plasma polymer coating resulted in the inhibition of bacterial growth.

\section{Discussion}

Plasma-polymerization is a versatile technique for the deposition of films with functional properties suitable for a wide range of applications [18] and in this work it was employed to coat $\beta$-TCP bioceramics. These biomaterials are excellent bone substitutes, and their intrinsic microporosity allows incorporation of drugs. However, control of drug release is complex and a new strategy has been evaluated.

Plasma polymer coatings deposited on top of polymers have been shown to have excellent barrier properties allowing to delay and control drug release [24, 25]. For biomedical applications, the polymers selected need to be, of course, non-toxic and biocompatible. Moreover, plasma polymerization allows for a one-step dry coating of the substrates. This, in 
the case of drug-loaded materials is an advantage in front of other methods such as ie. dipcoating as it avoids loss of drug in the coating solution during the coating treatment.

Conventional polyethylene glycol (PEG) or polyethylene oxide materials (repeating unit: $\left.-\mathrm{CH}_{2} \mathrm{CH}_{2} \mathrm{O}-\right)$ are often defined as non-fouling but when they are synthesized by plasma processes the chemical structure of the polymer obtained might be very different, with a certain degree of cross-linking, and presence of other moieties (i.e. ester, carbonyl, carboxyl and hydrocarbon groups) [26].

The coatings obtained here were produced on $\beta$-TCP from Diglyme as precursor at low pressure in sequential treatments ranging from 10 to $40 \mathrm{~min}$ of total treatment time (Figure 1). The coatings obtained revealed characteristic FTIR bands of PEG - C-O groups and $\mathrm{C}-\mathrm{H}$ (Figure 2). The $\mathrm{C} / \mathrm{O}$ surface ratio of the coatings was calculated from XPS data (Table 2), being around 3.5 for the four different coatings evaluated. The stoichiometric $\mathrm{C} / \mathrm{O}$ ratio of Diglyme is of 2, so the values obtained in this work indicate loss of oxygen moieties and increased cross-linking due to high fragmentation in the plasma as also found by E. Sardella et al. for similar plasma coatings obtained at high power on a polymeric substrate [26].

They designated this as "reduced PEG-character" in the plasma coatings contributed by cross-linking and oxygen loss from the Diglyme precursor. This is in agreement with the peak fitting of C1s XPS spectra of PP40 (Figure 3) where the C-C, C-H component at 285.0 $\mathrm{eV}$ is the most important component (relative fraction $\sim 50 \%$ ), closely followed by $\mathrm{C}-\mathrm{O}$ $(\sim 45 \%)$ attesting for the high hydrocarbon nature of PEG-like coatings deposited here. High hydrocarbon nature (C-C, C-H being the most abundant groups) was also observed in other works [26, 27].

It is not surprising to find this reduced PEG character, as in general, plasma polymers have different properties than those fabricated by conventional polymerization: the plasmapolymerized films are usually branched, highly cross-linked, insoluble, pinhole-free, and adhere well to most substrates [28, 29]. Due to these excellent properties, plasmapolymerized films have been utilized in a wide range of applications, such as protective coatings, biomedical materials, electronic and optical devices, adhesion promoters, etc.

The thickness of the coatings obtained was above $10 \mathrm{~nm}$ in all cases as revealed by the fact that $\mathrm{Ca}$ and $\mathrm{P}$ were not detected by XPS and as confirmed by FIB-SEM cross-section imaging (Figure 5). The PEG-like layer thickness (Figure 6) progressively increased with the total plasma treatment time in a nearly linear trend.

The surface structure of the $\beta$-TCP bioceramic evaluated in this work is highly complex with rough topography (Figure 6 top), where crystal grains and sintering necks can be observed. The plasma coating did not alter the topography of the surface and the pores were not covered with any of the coatings evaluated. The porosity of $\beta$-TCP and its hydrophilic chemistry led to fast water absorption, which did not allow contact angle measurement (Table 1). For the shortest treatment PP10 the coating was probably partially uneven, and some areas remained partially uncoated, still allowing for water absorption. Following plasma treatments of a total of $20 \mathrm{~min}$ or more (PP20, PP30, PP40), the static contact angles of the surface of $\beta$ TCP raised to values between 120 and $126^{\circ}$ as observed in Labay et al. [20]. This is shocking, considering that usually PEG-coatings are hydrophilic $\left(\theta \mathrm{s}<90^{\circ}\right)$, as confirmed by the contact angle values measured on flat silicon surfaces (Figure 3 ) with the same plasma coatings which varied between 74 and $79^{\circ}$.

Besides, dynamic contact angles were measured, which allowed calculating the contact 
angle hysteresis. The contact angle hysteresis is a measure for how well a drop of liquid sticks to the surface [30]. The hysteresis in contact angle obtained (Table 1) was rather high and very similar for all samples, indicating that the surface was heterogeneous. Considering the complex surface topography of $\beta$-TCP this can be attributed to roughness. This high hysteresis values are characteristic of surfaces where the drop does not roll-off easily [31], as confirmed by the pictures in Figure 3 showing pinning of the drop to the surface.

All this was indication of Wenzel's behaviour [32,33] occurring on the surface of plasma coated $\beta$-TCP (depicted in Figure 11$)$. The Wenzel relation $\left(\cos \theta^{*}=r \cos \theta\right)$ predicts that roughness enhances wettability which allowed calculating the apparent surface to be of roughness $(\mathrm{r})=2.6 \pm 0.4$ for this bioceramic, and coping well with the SEM images (Figure 5). Despite the great changes in surface chemistry altered wettability, the cytocompatibility was not compromised (Figure 8). Cell adhesion ( $6 \mathrm{~h}$ of cell culture) to the surface of PEG-like coated $\beta$-TCP in all conditions evaluated was comparable to that of the UT sample. The same occurred for the proliferation of the cells, which was the same to that of naked $\beta$-TCP (except only for PP40 at $24 \mathrm{~h}$ and 7 days, where a minor decrease in the number of cells was registered).

Despite PEG being widely acknowledged for its antifouling properties, our polymer layer was deposited by plasma in such conditions that lead to rather different chemistry than conventional PEG (less amount of C-O groups, more crosslinking, presence of other moieties such as $\mathrm{C}=\mathrm{O}$ ) so it has a "reduced" $\mathrm{PEG}$ character. Similar results were found when seeding 3T3 fibroblasts on flat surfaces plasma coated employing also Diglyme, where those conditions leading to reduced PEG character of the coating displayed suitable cell morphology, and homogeneous growth of the cells on the substrates with these characteristics, while no attachment at all was observed when PEG coatings were produced so the PEG character was retained and antifouling properties were ensured [26].

This is further confirmed by the SEM images on the cells adhered to $\beta$-TCP (Figure 8) at different time points, which are very well extended on the surface of $\beta$-TCP for all coatings, with visible fillopodia which reflect their good attachment to the surface. Many parameters influence cell behaviour on bioceramics [34], and parameters such as surface roughness, chemistry, solubility and crystallinity play a role. It seems clear that the thin layer produced here had suitable chemistry allowing, among others the protein adhesion required for further cell attachment, and therefore produced the minimum alterations in the biological behaviour of the samples.

Two different antibiotics were selected in this work: gentamicin, a wide spectrum antibiotic that is widely employed in orthopaedics, and ampicillin, which was selected for its wide spectrum of action and as reference for comparison with previous works [20, 35]. Both antibiotics followed distinct drug release profiles (Figure 9): On the one hand, ampicillin displayed burst release in the $1 \mathrm{st}$ h of release from UT-D $\beta$-TCP, and the stationary stage was reached after only $7 \mathrm{~h}$. On the other hand, gentamicin followed a more progressive release from UT-D and $\beta$-TCP, without reaching the stationary stage at least in the $24 \mathrm{~h}$ timeframe evaluated.

The recorded differences could be ascribed to the higher molecular weight and steric hindrance of gentamicin (Supplementary Material Figure S1), impairing the diffusion from the $\beta$-TCP matrix.

The plasma coatings evaluated here in both cases induced a progressively reduced amount of drug released, following this order: UT-D $\geq$ PP10-D $>$ PP20-D $>$ PP30-D $\geq$ PP40-D.

This could be explained by two different phenomena: i) etching processes occurring on 
the surface simultaneously to the plasma polymerization during plasma treatment, which might have eliminated a certain amount of the most superficial antibiotic adsorbed on the bioceramic; and ii) a barrier effect due to the polymer layer created. This copes well with the fact that lower amount was released when the plasma coating proceeded on for longer times (Figure 9). Fortunately, the reactivity with the plasma phase did not revert in a denaturation of the antibiotics, as all samples showed suitable inhibition of the Staphilococcus aureus bacterial growth (Figure 10). In general, after plasma processes aimed at modulation of drug release, the drugs keep their activity, as has been shown for different drugs (from anticancer to antibiotics), and varied plasma polymerization processes works.

Fitting of the release profiles to the Kopcha model indicates that the release occurring for both antibiotics clearly follows a diffusion mechanism (as shown by an A/B ratio $>1$ ).

Of course, to further control release from the plasma coating - to get closer to the 2-3 month sustained release required for treatment of osteomyelitis - thicker layers need to be produced, as shown for coatings on polymer films by Arefi-Khonsari et al. [36,37] or in our case in bioceramics from previous work [38]. In fact, a certain reduction in the release rate was recorded in the release of ampicillin from the coatings obtained at longer plasma treatment times (PP20-D, PP30-D and PP40-D) as had also been observed in a previous work of the group evaluating the same drug for coatings produced in similar conditions [20]. As observed in that case, it is expected that longer treatments produce further reduction in the initial release rate due to increased cross-linking of the polymer.

\section{Conclusions}

Antibiotic-releasing bioceramics with adequate drug release profiles and eliciting suitable biological response are of great interest. Plasma polymerization of Diglyme on drug-loaded $\beta$ Tricalcium Phosphate ( $\beta$-TCP) allowed reducing drug release by a dry solvent-free method. PEG-like polymer coatings with low retention of the PEG character were obtained on microporous $\beta$ TCP. This avoided the typical antifouling properties of PEG coatings. Plasma polymerization time dependency was observed in the coating thickness (ranging from 10 $\mathrm{nm}$ to $40 \mathrm{~nm}$ ) which in turn was related to the total amount of drug released. In certain conditions the antibiotic release profile was modified. Ampicillin and gentamicin antibiotics retained their antimicrobial activity intact after being released from the $\beta$-TCP substrates, confirming the suitability of the technique for coating the drug-loaded ceramic matrices.

Despite the polymer produced being hydrophilic in nature, unexpected surface hydrophobicity following Wenzel's behaviour was found on $\beta$-TCP. This was due to the significant roughness of the surface of this bioceramic. Still, the good cytocompatibility of $\beta$-TCP (adhesion and proliferation of SaOS-2) remained unaltered. The research undertaken allowed unravelling the characteristics of plasma coatings on calcium phosphate ceramics and advancing towards the design of drug delivery matrices with suitable biological and microbiological behaviour.

\section{Acknowledgements}

Authors acknowledge the Spanish Government for financial support through Project MAT2015-65601-R, co-funded by the EU through European Regional Development Funds, and Ramon y Cajal fellowship of Cristina Canal. Support for the research of Maria Pau Ginebra was 
received through the "ICREA Academia" prize for excellence in research, funded by the Generalitat de Catalunya. The European Union is acknowledged for the DocMASE PhD scholarship of Kanupriya Khurana.

\section{References}

[1] Osteomyelitis Symptoms, Treatment, Causes - What is the treatment for osteomyelitis? - MedicineNet, (n.d.).

[2] V. Delfosse, A. El Warrak, P. Clerfond, B. Lussier, Article Clinical investigation of local implantation of gentamicin-impregnated collagen sponges in dogs, Can Vet J. 5252 (2011) 627-630.

[3] S. Seber, I. Günal, E. Göktürk, Antibiotic-impregnated xenografts in the treatment of chronic osteomyelitic cavities. Seven cases followed for 3 to 5 years., Int. Orthop. 22 (1998) 197-9.

[4] Z. Ruszczak, W. Friess, Collagen as a carrier for on-site delivery of antibacterial drugs., Adv. Drug Deliv. Rev. 55 (2003) 1679-98.

[5] J. Gaudias, Les limites de l'antibiothérapie locale dans le traitement de l'infection ostéo-articulaire, Eur. J. Orthop. Surg. Traumatol. 4 (1994) 119-121.

[6] M. Ouédraogo, R. Semdé, I.T. Somé, R. Traoré/Ouédraogo, I.P. Guissou, V. Henschel, J. Dubois, K. Amighi, B. Evrard, Monoolein- water liquid crystalline gels of gentamicin as bioresorbable implants for the local treatment of chronic osteomyelitis: In vitro characterization, Drug Dev. Ind. Pharm. 34 (2008) $753-760$. [7] A.J. Swieringa, J.H.M. Goosen, F.G.A. Jansman, N.J.A. Tulp, In vivo pharmacokinetics of a gentamicin-loaded collagen sponge in acute periprosthetic infection: Serum values in 19 patients, Acta Orthop. 79 (2008) 637-642.

[8] A.M. Cruz, L. Rubio-Martinez, T. Dowling, New antimicrobials, systemic distribution, and local methods of antimicrobial delivery in horses, Vet. Clin. North Am. Equine Pract. 22 (2006) 297-322.

[9] Z. Ruszczak, Effect of collagen matrices on dermal wound healing., Adv. Drug Deliv. Rev. 55 (2003) $1595-611$.

[10] G. Hirsbrunner, A. Steiner, Treatment of infectious arthritis of the radiocarpal joint of cattle with gentamicin-impregnated collagen sponges., Vet. Rec. 142 (1998) 399-402.

[11] B. Liu, D. Lun, Current Application of $\beta$-tricalcium Phosphate Composites in Orthopaedics, Orthop. Surg. 4 (2012) 139-144.

[12] A.A. Mirtchi, J. Lemaitre, N. Terao, Calcium phosphate cements: study of the $\beta$-tricalcium phosphate monocalcium phosphate system, Biomaterials. 10 (1989) 475-480.

[13] J. Wang, W. Chen, Y. Li, S. Fan, J. Weng, X. Zhang, Biological evaluation of biphasic calcium phosphate ceramic vertebral laminae, Biomaterials. 19 (1998) 1387-1392.

[14] Y.L. Chang, C.M. Stanford, J.C. Keller, Calcium and phosphate supplementation promotes bone cell mineralization: implications for hydroxyapatite (HA)-enhanced bone formation., J. Biomed. Mater. Res. 52 (2000) 270-8.

[15] L.D. Silverman, L. Lukashova, O.T. Herman, J.M. Lane, A.L. Boskey, Release of gentamicin from a tricalcium phosphate bone implant, J. Orthop. Res. 25 (2007) 23-29.

[16] M. Neumann, M. Epple, Composites of Calcium Phosphate and Polymers as Bone Substitution Materials, Eur. J. Trauma. 32 (2006) 125-131.

[17] R.A. Perez, H.-W. Kim, M.-P. Ginebra, Polymeric additives to enhance the functional properties of calcium phosphate cements., J. Tissue Eng. 3 (2012) 2041731412439555.

[18] R. Morent, N. De Geyter, T. Jacobs, S. Van Vlierberghe, P. Dubruel, C. Leys, E. Schacht, Plasma processes and polymers., Wiley-VCH Verlag \& Co. KGaA, 2004.

[19] F. Benítez, E. Martínez, J. Esteve, Improvement of hardness in plasma polymerized

hexamethyldisiloxane coatings by silica-like surface modification, Thin Solid Films. 377-378 (2000) $109-114$.

[20] C. Labay, J. Buxadera-Palomero, M. Avilés, C. Canal, M.P. Ginebra, Modulation of release kinetics by plasma polymerization of ampicillin-loaded $\beta$-TCP ceramics, J. Phys. D: Appl. Phys. 49 (2016).

[21] M.-P. Ginebra, E. Fernandez, F.C.M. Driessens, J.A. Planell, Modeling of the Hydrolysis of aTricalcium Phosphate, J. Am. Ceram. Soc. 82 (2004) 2808-2812.

[22] F. Brétagnol, M. Lejeune, A. Papadopoulou-Bouraoui, M. Hasiwa, H. Rauscher, G. Ceccone, P. Colpo, F. Rossi, Fouling and non-fouling surfaces produced by plasma polymerization of ethylene oxide monomer, Acta Biomater. 2 (2006) 165-172.

[23] X. Deng, A. Nikiforov, D. Vujosevic, V. Vuksanovic, B. Mugoša, U. Cvelbar, N. De Geyter, R. Morent, 
C. Leys, Antibacterial activity of nano-silver non-woven fabric prepared by atmospheric pressure plasma deposition, 2015.

[24] S. Bhatt, J. Pulpytel, M. Mirshahi, F. Arefi-Khonsari, Plasma co-polymerized nano coatings e As a biodegradable solid carrier for tunable drug delivery applications, Polymer (Guildf). 54 (2013) 4820-4829.

[25] K. (Ken) Ostrikov, U. Cvelbar, A.B. Murphy, Plasma nanoscience: setting directions, tackling grand challenges, J. Phys. D. Appl. Phys. 44 (2011) 174001.

[26] E. Sardella, R. Gristina, G.S. Senesi, R. D’Agostino, P. Favia, Homogeneous and micro-patterned plasma-deposited PEO-like coatings for biomedical surfaces, Plasma Process. Polym. 1 (2004) 63-72.

[27] R. d'Agostino, P. Favia, C. Oehr, M.R. Wertheimer, Plasma Processes and Polymers, Plasma Process. Polym. 1 (2004) 11-12.

[28] C. Vautrin-U1, F. Roux, C. Boisse-Laporte, J.L. Pastol, A. Chausse, Hexamethyldisiloxane (HMDSO)plasma-polymerised coatings as primer for iron corrosion protection: influence of RF bias, J. Mater. Chem. 12 (2002) 2318-2324.

[29] F. Arefi, V. Andre, P. Montazer-Rahmati, J. Amouroux, Plasma polymerization and surface treatment of polymers, Pure Appl. Chem. 64 (1992) 715-723.

[30] J.C. Berg "Wettability”, ed. Marcel Dekker, New York, 1993

[31] B.P. van der Wal, Static and dynamic wetting of porous Teflon ${ }^{\circledR}$ surfaces Wal, Bouwe Pieter van der, s.n.], 2017.

[32] R.N. Wenzel, Resistance of solid surfaces to wetting by water, Ind. Eng. Chem. 28 (1936) 988-994.

[33] S. Samavedi, A.R. Whittington, A.S. Goldstein, Calcium phosphate ceramics in bone tissue engineering: A review of properties and their influence on cell behavior, Acta Biomater. 9 (2013) 8037-8045.

[34] C. Labay, J.M. Canal, M. Modic, U. Cvelbar, M. Quiles, M. Armengol, M.A. Arbos, F.J. Gil, C. Canal, Antibiotic-loaded polypropylene surgical meshes with suitable biological behaviour by plasma functionalization and polymerization., Biomaterials. 71 (2015) 132-44.

[35] S. Bhatt, F. Valamanesh, J. Pulpytel, R. Lo Dico, A. Baiyukha, I. Al-dybiat, M. Pocard, F. ArefiKhonsari, M. Mirshahi, Radio-frequency plasma polymerized biodegradable carrier for in vivo release of cisplatinum, Oncotarget. 7 (2016) 58121-58132.

[36] S. Bhatt, J. Pulpytel, F. Aref-Khonsari, Low and atmospheric plasma polymerisation of nanocoatings for bio-applications, Surface Innovations 3 (2015) 63-83.

[37] S. Bhatt, J. Pulpytel, M. Mirshahi, F. Arefi-Khonsari, Catalyst-Free Plasma-Assisted Copolymerization of Poly( $\varepsilon$-caprolactone)-poly(ethylene glycol) for Biomedical Applications, ACS Macro Lett. 1 (2012) $764-767$. [38] C. Canal, K. Khurana, S. Gallinetti, S. Bhatt, J. Pulpytel, F. Arefi-Khonsari, M.P. Ginebra, Design of calcium phosphate scaffolds with controlled simvastatin release by plasma polymerisation, Polym. 92 (2016) 170-178. 


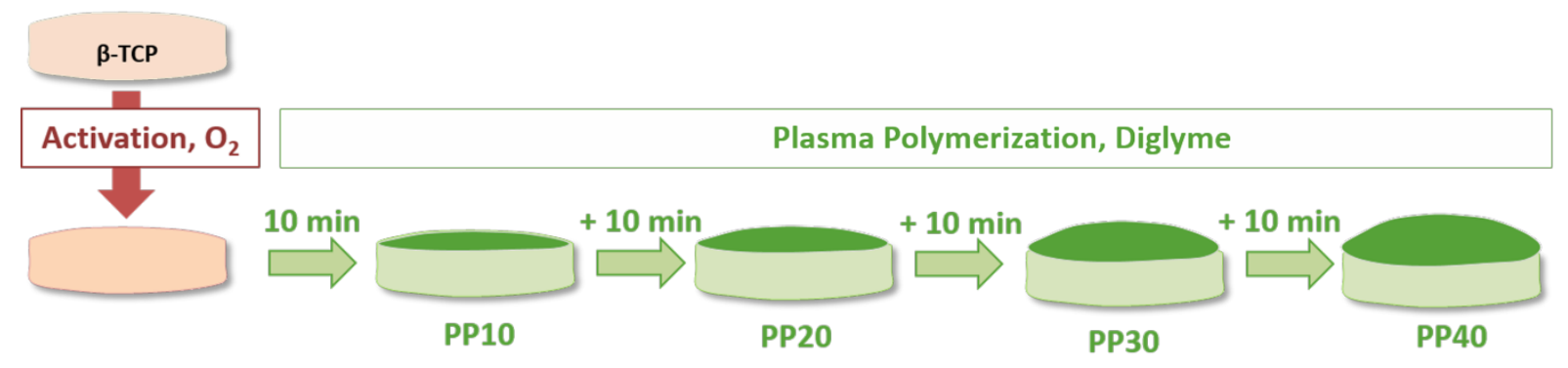

Figure 1: Scheme of the experimental layout employed to obtain PEG-like coatings on $\beta$-TCP discs. Low pressure plasma: $1^{\text {st }}$ activation of the surface by $\mathrm{O}_{2}$ plasma and $2^{\text {nd }}$ plasma polymerization $\mathrm{Ar}$ as carrier with Diglyme monomer, with 10 min sequential treatments named as plasma polymerization for $10 \mathrm{~min}$ (PP10), $20 \mathrm{~min}$ (PP20), $30 \mathrm{~min}$ (PP30) and $40 \mathrm{~min}$ (PP40). 


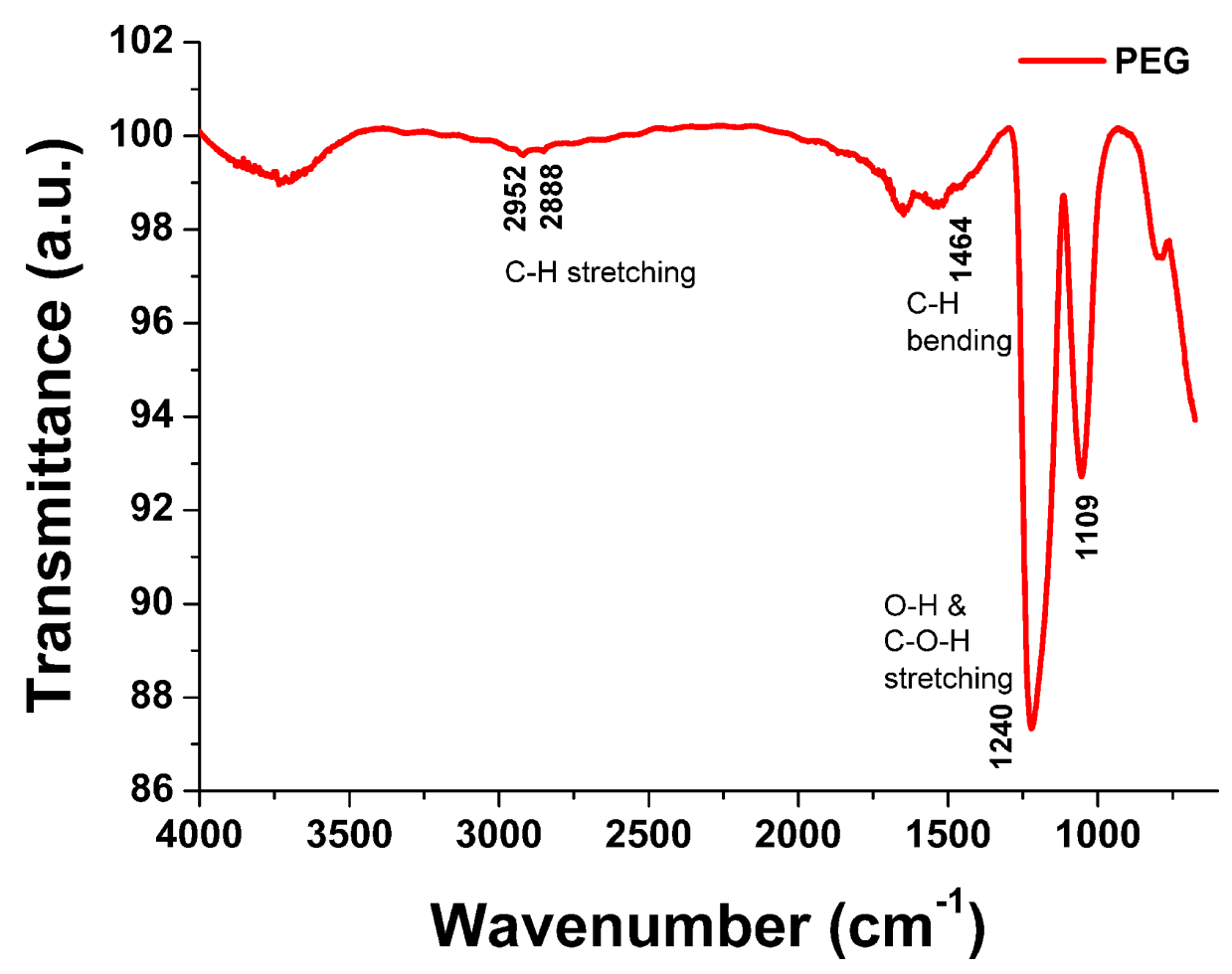

Figure 2: FTIR spectrum of the plasma polymer (PP40) obtained on Si wafer as model surface.

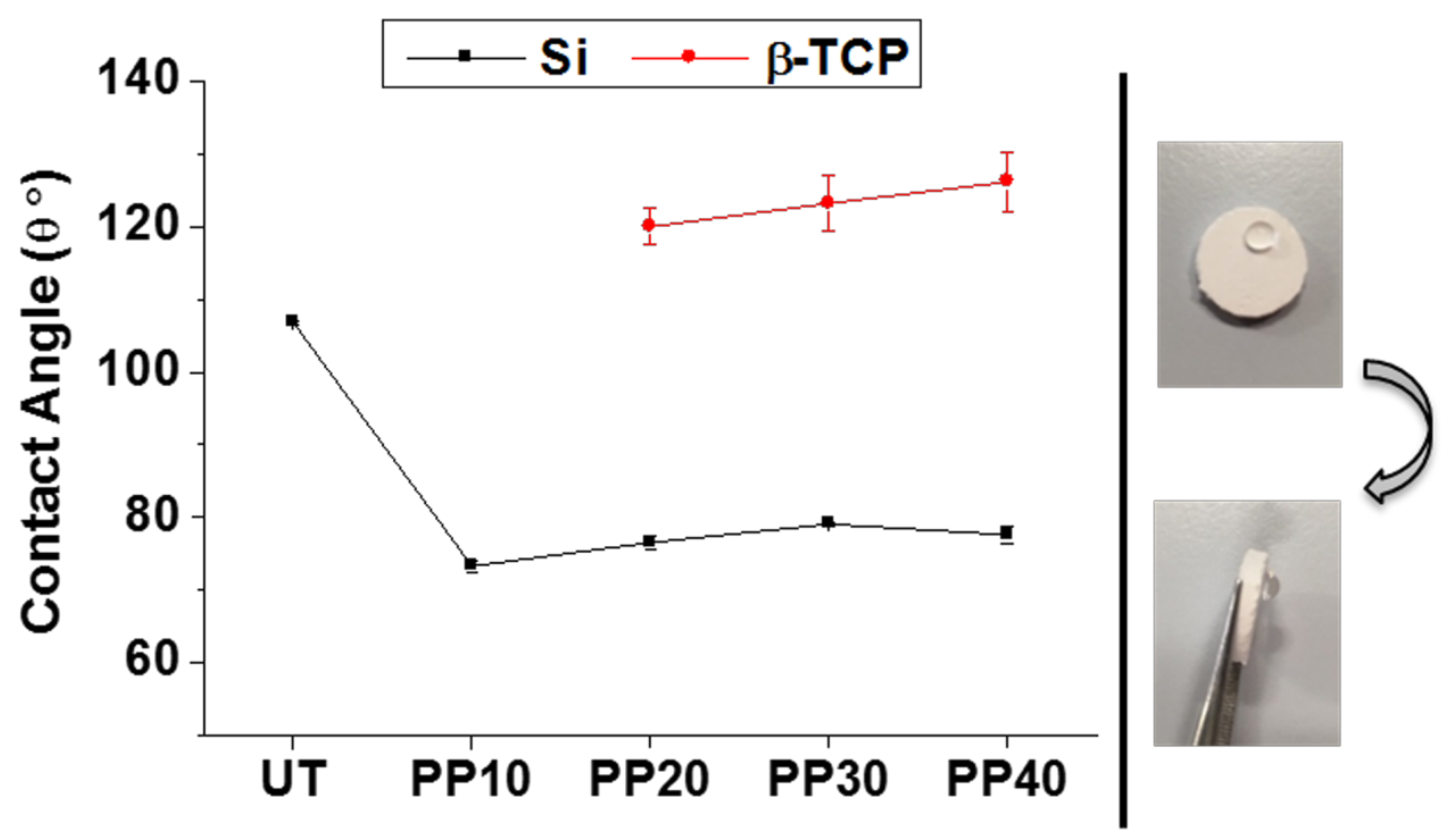

Figure 3: Wettability of two plasma-polymerized substrates: silicon wafer (employed as flat model surface) and $\beta$ TCP samples (UT and PP10 were not measurable due to hydrophilicity). Images of the droplet on the surface of PP40 with the sample lying flat, or held vertical. 


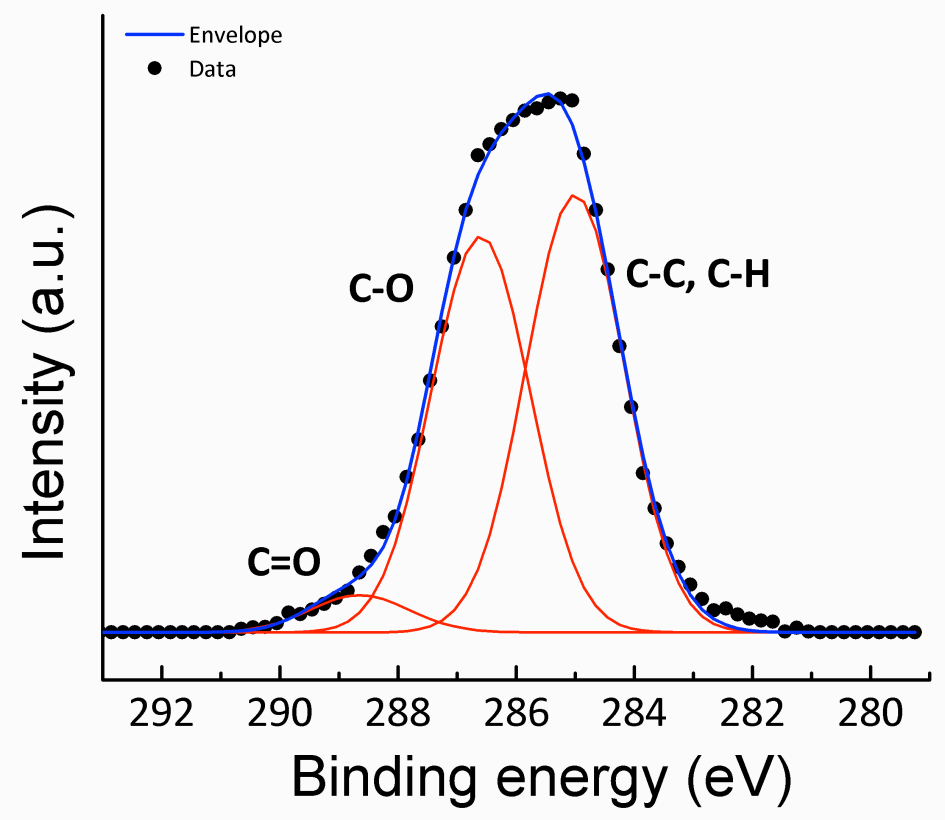

Figure 4: $\mathrm{C}_{1 \text { s }}$ spectra and peak decomposition of the PEG-like plasma polymer coating on $\beta$-TCP for PP40. 


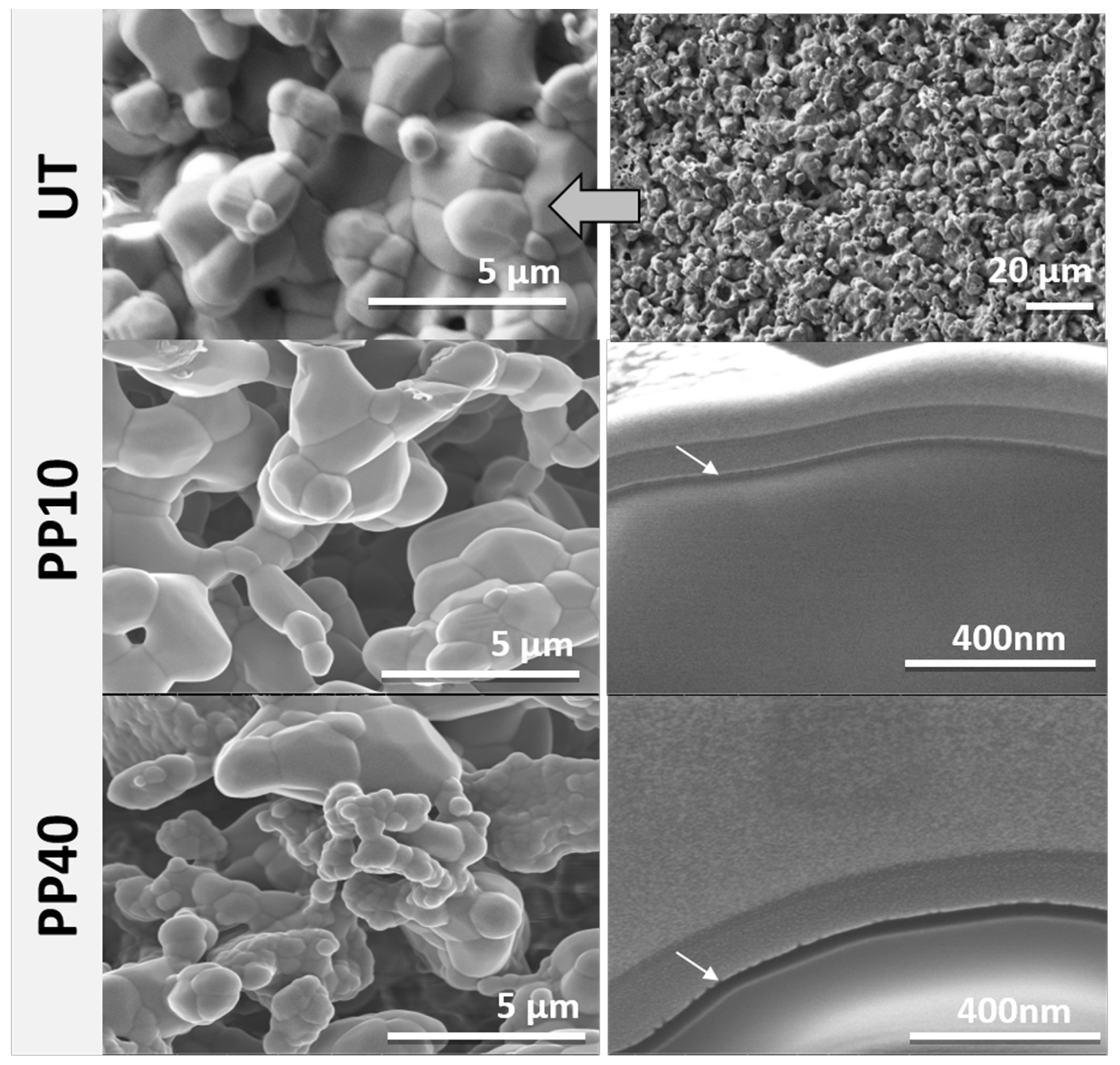

Figure 5: Scanning Electron Micrographs of $\beta$-TCP untreated surfaces at two different magnifications (top) and of the surface of $\beta$-TCP at different polymerization conditions PP10 and PP40 (left column) with their corresponding transversal sections obtained by FIB (right column). Arrows indicate the polymer coatings. (Other plasma polymer coatings: PP20, PP30 not shown). 


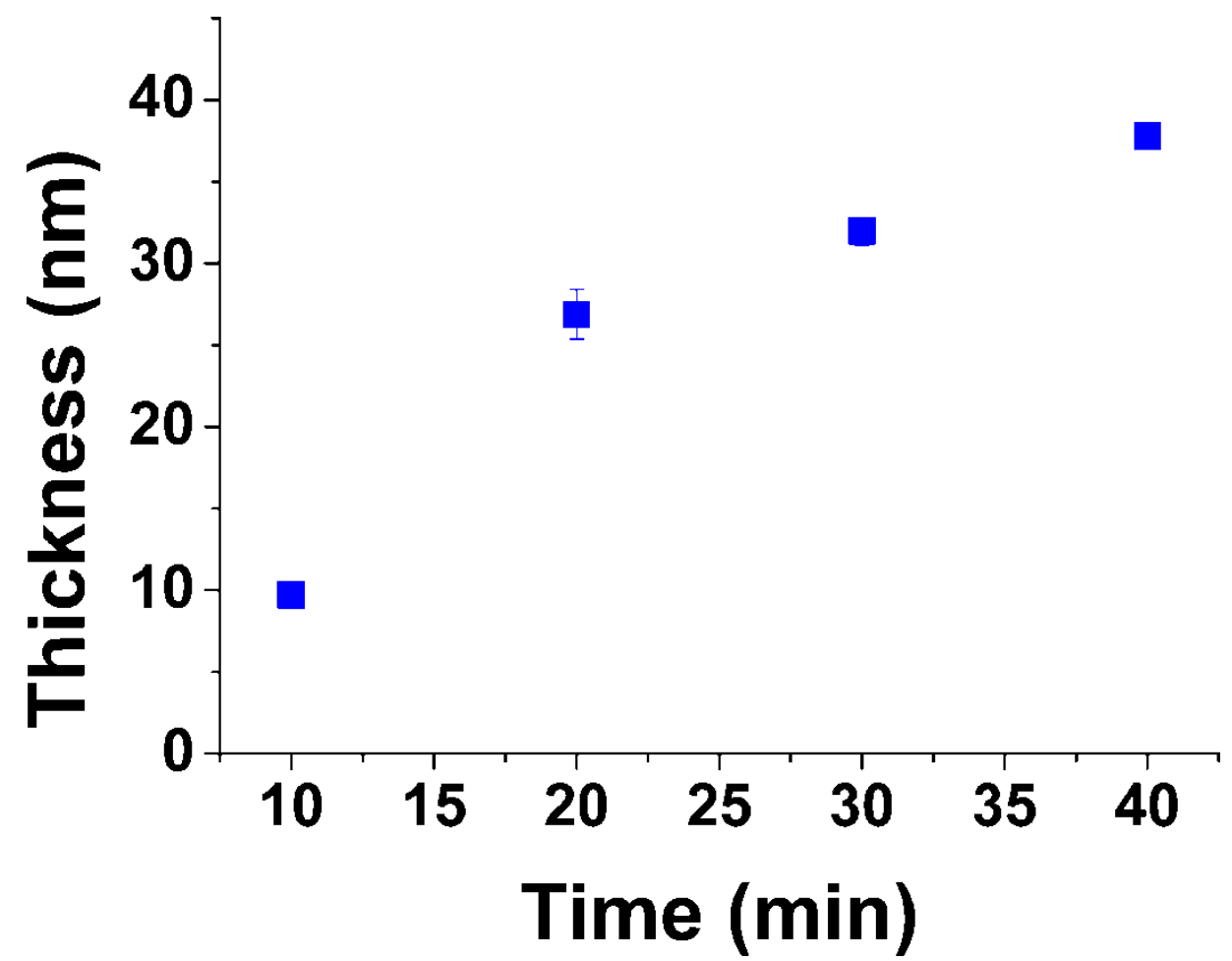

Figure 6: Thickness of the PEG-like layer obtained by different plasma polymerization treatments on the surface of $\beta$-TCP as a function of the total treatment time.

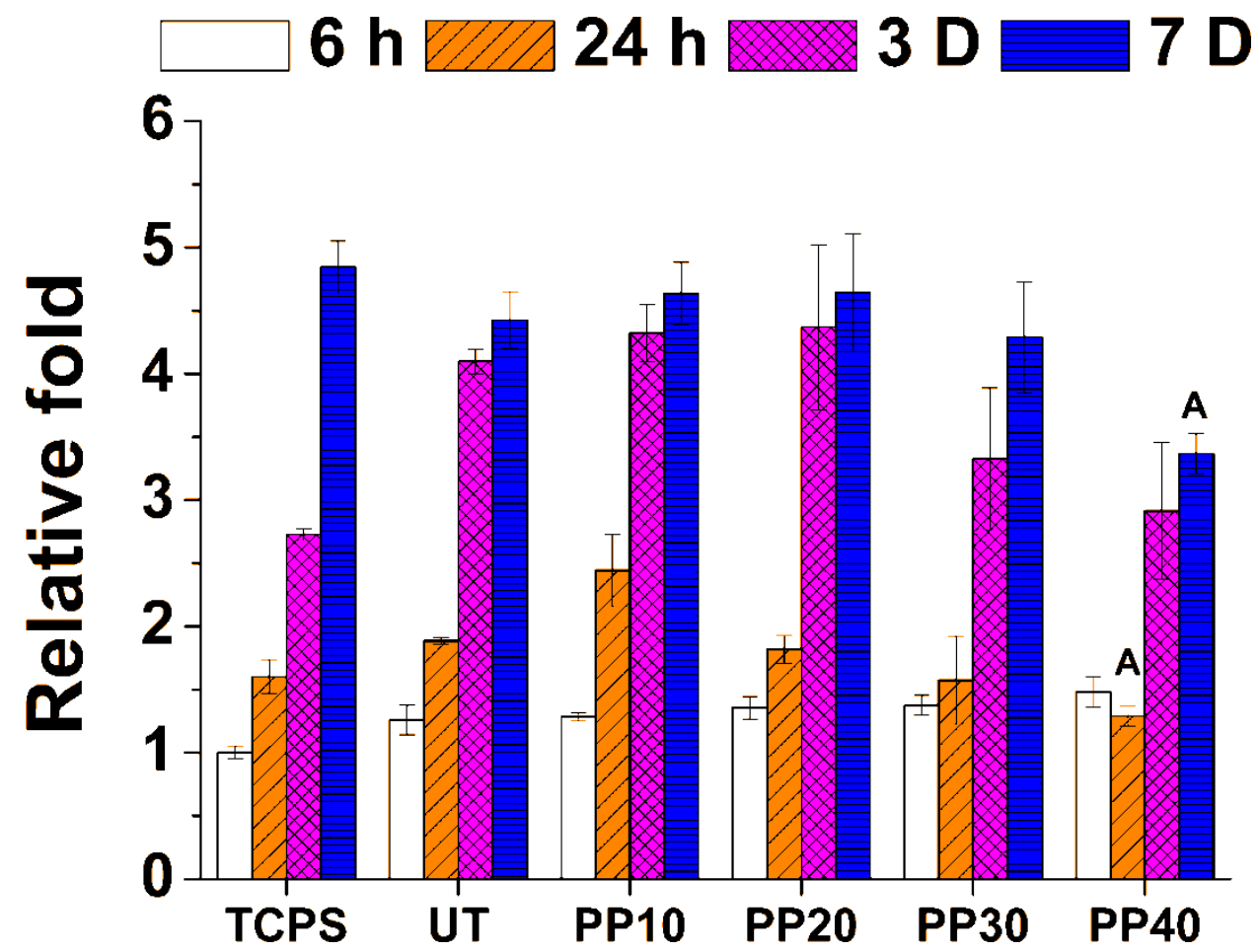

Figure 7: SaOS-2 cells relative fold growth on untreated $\beta$-TCP and plasma-polymerized $\beta$-TCP at different cell culture times. (A indicates significant differences with respect to $\beta$-TCP, P $>0.05$ ). TCPS accounts for "Tissue culture polystyrene" which is taken as a positive control. 


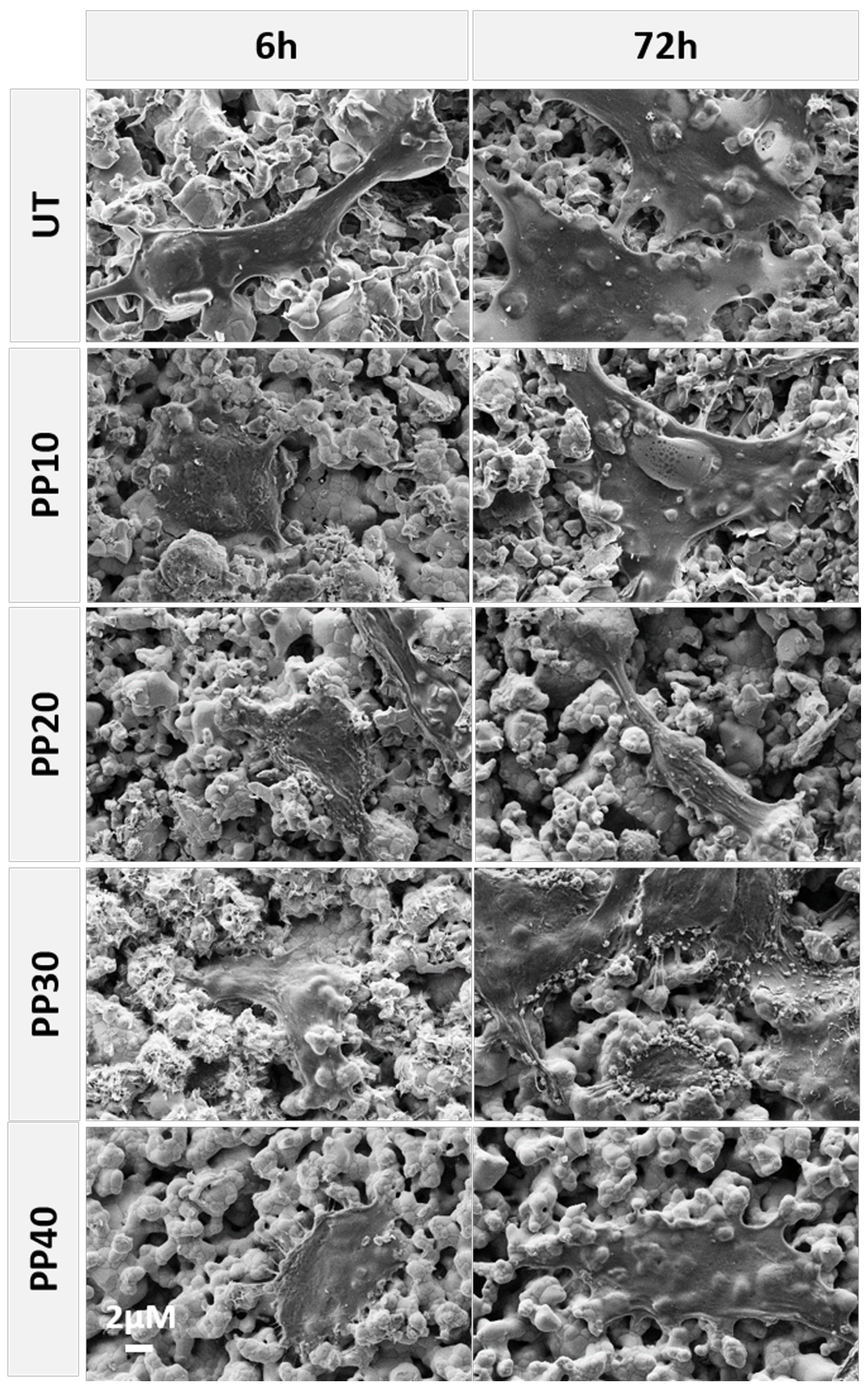

Figure 8: Scanning electron micrographs of untreated and plasma-coated $\beta$-TCP seeded with SaOS-2cells for either $6 \mathrm{~h}$ (left) or $72 \mathrm{~h}$ (right). 


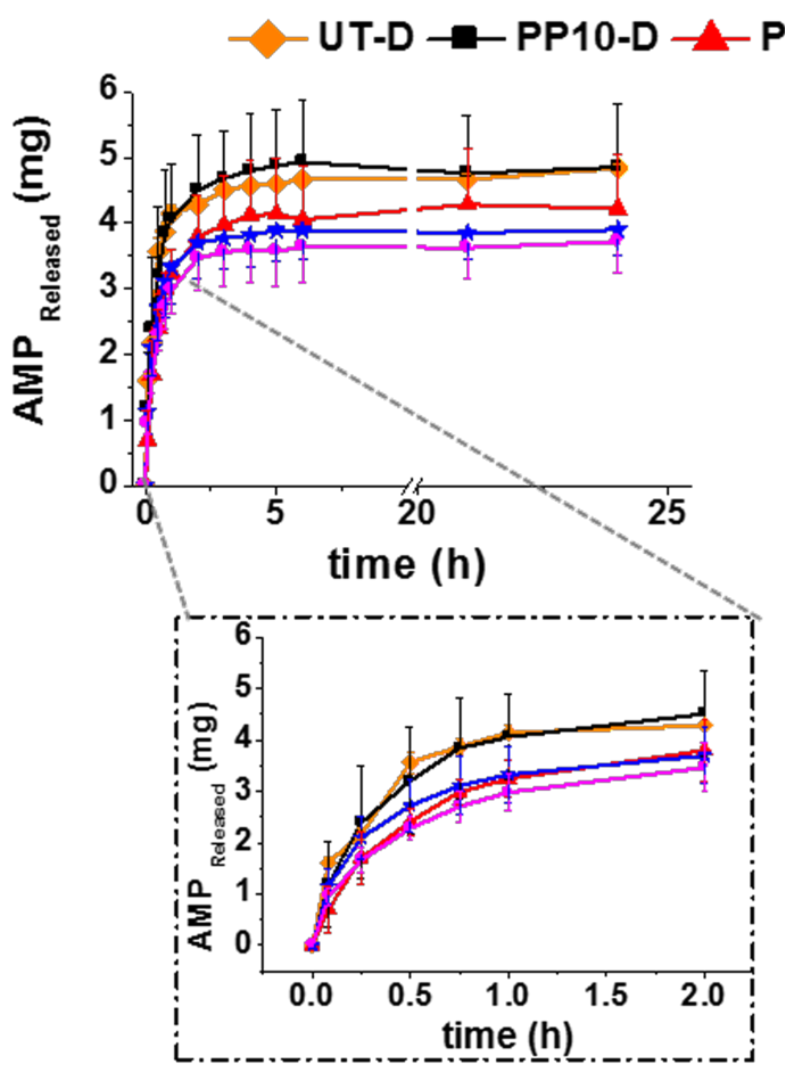

PP20-D $\star$ - PP30-D - - PP40-D
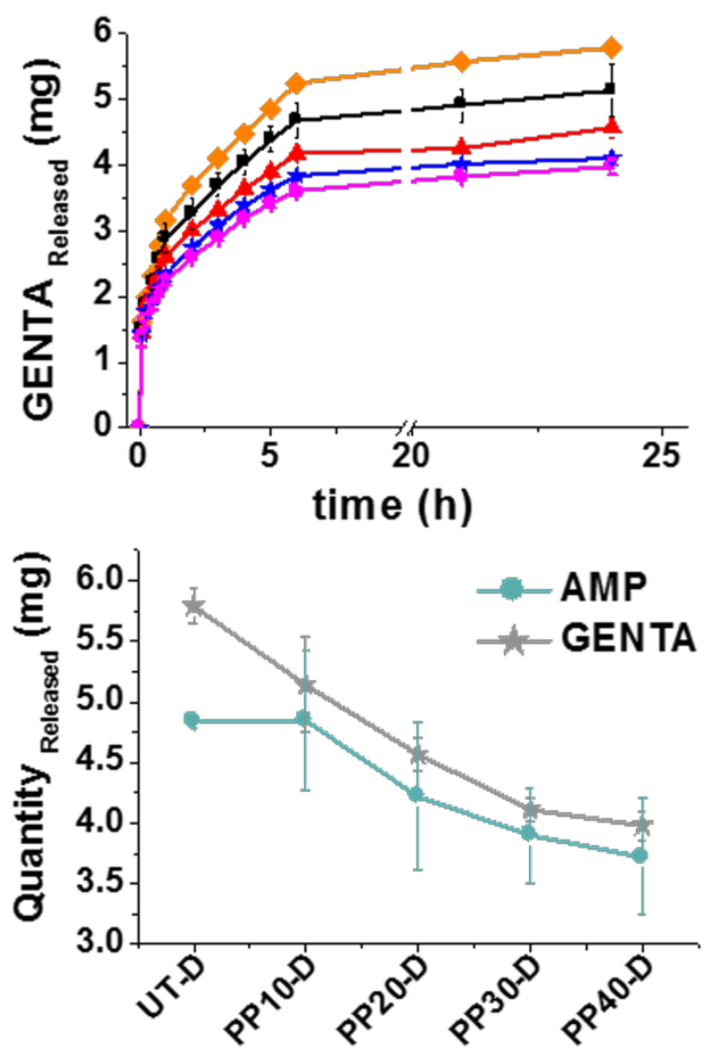

Figure 9: Release kinetics of ampicillin and gentamicin (top) for $24 \mathrm{~h}$, and total quantity released for both ampicillin and gentamicin (labelled with " $\mathrm{D}$ " for drug) for untreated and different treatments (bottom right). 

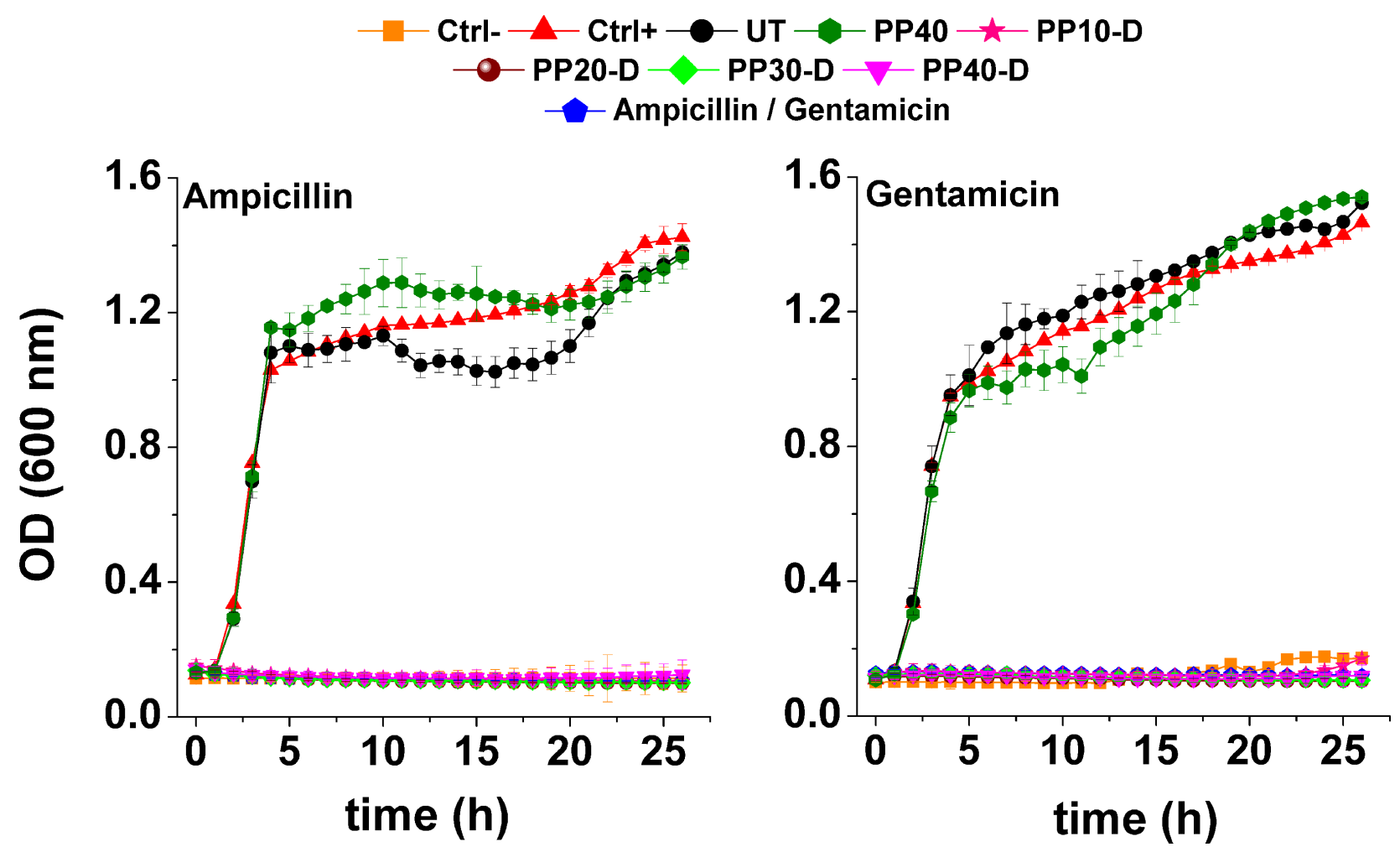

Figure 10: Continuous monitoring of the optical density of Staphilococcus Aureus bacterial suspensions in contact with ampicillin (AMP) and gentamicin (GENTA) loaded $\beta$ - TCP ceramics either untreated (UT) or plasma polymerized (PP40, PP10-D, PP20-D, PP30-D and PP40-D) or the suitable controls (in contact with S.aureus growth activity during $26 \mathrm{~h}$.

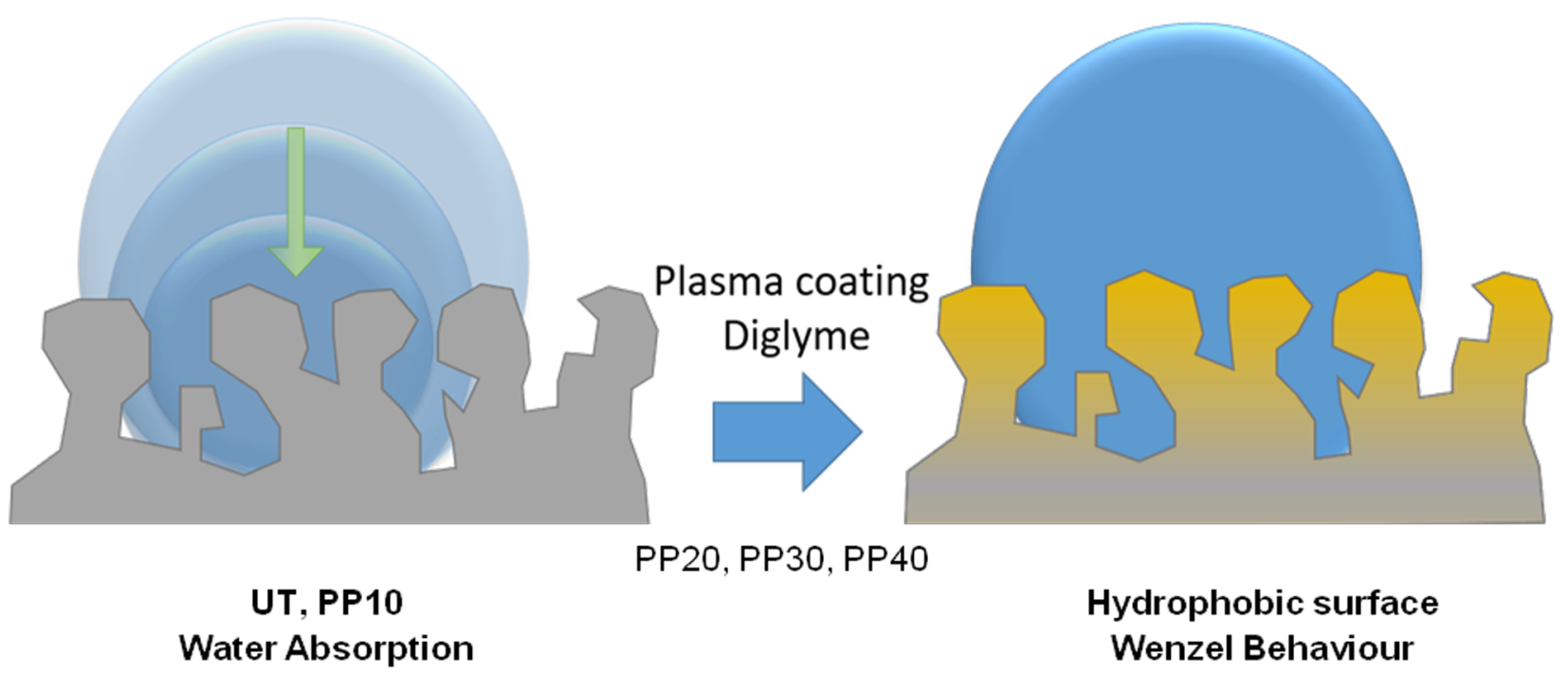

Figure 11: Representation of the wetting behaviour of $\beta$-TCP bioceramics before and after plasma polymerization of PEG-like layers. 
Table 1: Influence of polymerization conditions evaluated on $\beta$-TCP, static contact angle and Dynamic advancing and receding contact angles and contact angle hysteresis of $\beta$-TCP samples untreated (UT) or with different plasma treatments.

\begin{tabular}{|c|c|c|c|c|c|}
\hline & $t_{\text {plasma }}{ }^{\text {tot }}$ (min) & $\theta_{s}(\stackrel{0}{)})$ & $\theta_{\text {adv }}(\stackrel{\circ}{)})$ & $\boldsymbol{\theta}_{\text {rec }}(\stackrel{0}{)})$ & 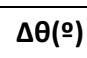 \\
\hline UT & 0 & $*$ & $*$ & $*$ & - \\
\hline PP10 & 10 & $*$ & $*$ & * & - \\
\hline PP20 & 20 & $120.03 \pm 2.51$ & $128.92 \pm 1.04$ & $65.61 \pm 4.18$ & 63.31 \\
\hline PP30 & 30 & $123.27 \pm 3.76$ & $125.32 \pm 3.42$ & $59.97 \pm 6.17$ & 65.35 \\
\hline PP40 & 40 & $126.20 \pm 3.99$ & $119.45 \pm 1.83$ & $57.08 \pm 5.67$ & 62.37 \\
\hline
\end{tabular}

Table 2: Elemental composition (in percentage) and $\mathrm{C} / \mathrm{O}$ atomic ratio obtained by XPS $\beta$-TCP samples with different plasma treatments.

\begin{tabular}{cccccc}
\hline & & \multicolumn{2}{c}{ Atomic percentages (\%) } & \multicolumn{2}{c}{ Atomic ratio } \\
\hline Codes & $\mathbf{C}_{\mathbf{1 s}}$ & $\mathbf{O}_{\mathbf{1 s}}$ & $\mathbf{C a}_{\mathbf{2}}$ & $\mathbf{P}_{\mathbf{2}}$ & $\mathbf{C} / \mathbf{O}$ \\
\hline $\mathbf{U T}$ & 12.4 & 56.1 & 18.8 & 12.7 & 0.22 \\
\hline PP10 & 77.5 & 22.5 & - & - & 3.44 \\
\hline PP20 & 77.3 & 22.7 & - & - & 3.41 \\
\hline PP30 & 78.2 & 21.8 & - & - & 3.59 \\
\hline PP40 & 77.7 & 22.3 & - & 3.47 \\
\hline
\end{tabular}

Table 3: Ampicillin or Gentamicin released percentage $\beta$-TCP discs after $24 \mathrm{~h}$ and kopcha kinetics for the release kinetics.

\begin{tabular}{|c|c|c|c|c|c|c|c|c|c|c|}
\hline & \multicolumn{5}{|c|}{ Ampicillin } & \multicolumn{5}{|c|}{ Gentamicin } \\
\hline & \multicolumn{5}{|c|}{ Kopcha's Kinetics } & \multicolumn{5}{|c|}{ Kopcha's Kinetics } \\
\hline & $\begin{array}{c}\text { AMP }_{\text {released }} \\
(\%)\end{array}$ & $\mathrm{R}^{2}$ & $\mathrm{~A}$ & $\mathrm{~B}$ & $\begin{array}{l}\mathrm{A} / \mathrm{B} \\
(>1)\end{array}$ & $\begin{array}{l}\text { GENTA } \\
\text { released }(\%)\end{array}$ & $\mathrm{R}^{2}$ & $\mathrm{~A}$ & B & $\begin{array}{l}\mathrm{A} / \mathrm{B} \\
(>1)\end{array}$ \\
\hline UT & $99.6 \pm 0.5$ & 0.983 & 0.736 & 0.022 & 32.6 & $99.3 \pm 0.9$ & 0.987 & 0.540 & 0.015 & 35.79 \\
\hline PP10 & $99.8 \pm 1.7$ & 0.982 & 0.586 & 0.010 & 55.8 & $98.7 \pm 2.1$ & 0.986 & 0.512 & 0.015 & 33.70 \\
\hline PP20 & $96.9 \pm 1.3$ & 0.994 & 0.499 & 0.012 & 39.0 & $88.1 \pm 4.1$ & 0.975 & 0.506 & 0.016 & 30.53 \\
\hline PP30 & $96.2 \pm 2.2$ & 0.993 & 0.559 & 0.016 & 34.8 & $80.9 \pm 6.7$ & 0.970 & 0.475 & 0.016 & 29.73 \\
\hline PP40 & $80.7 \pm 8.0$ & 0.997 & 0.458 & 0.011 & 39.7 & $78.9 \pm 2.8$ & 0.975 & 0.442 & 0.015 & 30.32 \\
\hline
\end{tabular}

